
\title{
25 Research Sourere \\ Nutritional Predictors of Mortality after Discharge in Older Patients with type 2 Diabetes
}

\section{Mileni Vanti Beretta ( $\nabla$ mileni.nutri@gmail.com )}

Universidade Federal do Rio Grande do Sul https://orcid.org/0000-0002-9246-1562

\section{Camila Nery da Silva}

Universidade Federal do Rio Grande do Sul

Juliane Viero Feldman

Universidade Federal do Rio Grande do Sul

\section{Ticiana da Costa Rodrigues}

Hospital de Clinicas de Porto Alegre

\section{Research}

Keywords: type 2 diabetes, calf circumference, mortality, adductor pollicis muscle thickness malnutrition

Posted Date: August 13th, 2020

DOl: https://doi.org/10.21203/rs.3.rs-53340/v1

License: (9) This work is licensed under a Creative Commons Attribution 4.0 International License.

Read Full License 
Nutritional predictors of mortality after discharge in older patients with type 2 diabetes

Mileni Vanti Beretta ${ }^{1-3}$

Camila Nery da Silva ${ }^{1}$

Juliane Viero Feldman ${ }^{1}$

Ticiana da Costa Rodrigues ${ }^{1-3}$

1. Universidade Federal do Rio Grande do Sul, Brazil

2. Programa de Pós-Graduação de Ciências médicas: endocrinologia, UFRGS.

3. Hospital de Clínicas de Porto Alegre, Porto Alegre, Brazil

\section{Correspondence to:}

Mileni V Beretta

Divisão de Endocrinologia,

Hospital de Clínicas de Porto Alegre

Rua Ramiro Barcelos, 2350,

Prédio $12,4^{\circ}$ andar

90035-003 - Porto Alegre, RS, Brasil

mileni.nutri@gmail.com 
Background: Older patient with type 2 diabetes (T2D) and malnutrition have a greater chance of negative events during hospitalization and a higher risk of mortality. The aim of this study was to investigate nutritional markers as mortality predictors following discharge hospitalized older patients with T2D.

Methods: This is a prospective cohort study with follow-up of four years. All patients were subjected to Mini Assessment Nutrition, Subjective Global Assessment, calf circumference, arm circumference and adductor pollicis muscle thickness, obtained all within $48 \mathrm{~h}$ of admission. Mortality data were verified by medical registry and analyzed using Cox-proportional hazard models and survival curves.

Results: 311 patients were included; the mean age was 71.35 years. There were $113(36.3$ $\%$ ) deaths in the follow-up period. Nutritional status evaluated according to BMI identified $54.5 \%(n=168)$ were overweight, for other hand the MAN identified $45.7 \%$ of patients were at risk of malnutrition and $37.7 \%$ malnutrition and the SGA identify $61.7 \%$ $(\mathrm{n}=192)$ presented normal nutrition in admission. Malnutrition patients $(\mathrm{OR}=2.02)$, with low calf circumference $(\mathrm{OR}=1.43)$ or with APMT less than 5 th percentile (2.33) were associated with post-discharge mortality.

Conclusion: Malnutrition, reduced calf circumference and reduced APMT were nutritional predictors of mortality after hospital discharge in older patients with diabetes

Keywords: type 2 diabetes; calf circumference; mortality; adductor pollicis muscle thickness malnutrition. 


\section{Introduction}

Older people with type 2 diabetes (T2D) are more susceptible to adverse events and complications during a hospital stay, which can cause a to increased length of stay, malnutrition, functional decline, unscheduled surgeries and higher rates mortality. ${ }^{1-3}$ The prevalence of malnutrition in older patients with T2D at admission can be vary between $18,5 \%$ a $22.7 \% .^{4-6}$

In fact, the body composition of patients with diabetes has particularities, such as: high body fat, lower strength and muscle mass ${ }^{7-9}$ and greater risk for sarcopenia ${ }^{4}$. Thus, the nutritional assessment of these patients needs to be carried out with caution and using tools that make it possible to detect body changes, functional changes as well as changes in nutritional status.

In the hospital routine, different tools are used to identify nutritional risk and assessment nutritional status such Subjective Global Assessment (SGA) ${ }^{10}$ and Mini Assessment Nutrition (MAN) ${ }^{11}$, but most tool no quantify into account the muscle mass or functional capacity. For this purpose, for many years some anthropometric variables have been used such as: mid-arm circumference $(\mathrm{MAC})^{12}$., calf circumference $(\mathrm{CC})^{13}$ and adductor pollicis muscle thickness (AMPT) ${ }^{14}$ in different populations, but particularly in the older patients.

The tool SGA, it has been validated for different populations and clinical situations, it is considered a fast application tool with good prediction for nutritional status, length of stay and mortality ${ }^{15}$ Previous studies show good prediction in postoperative outcomes. ${ }^{16}$ The MNA was specifically structured to evaluate the older patient $^{11}$, however, it requires a longer time for application. Was evaluated as a predictor of mortality in older patients, not exclusively with T2D in Italy ${ }^{17}$. Others anthropometric measurements such as WC and MAC are sensitive in assessing muscle quantity, as well as APMT. Studies in Chinese ${ }^{18}$ and Taiwanese ${ }^{19}$ populations have identified WC ${ }^{18,19}$ and $\mathrm{MAC}^{18,20}$ such predictor of mortality. 
Faced with this, this study aims to assess whether SGA, MNA, CC, MAC and APMT can predict mortality after discharge from this population.

\section{Methods}

A sample of patients of both sexes, hospitalized in a clinical ward of a university hospital in Southern Brazil was evaluated from July 2015 to December 2016 as part of the cohort study entitled: Clinical and nutritional predictors of mortality and readmission in older patients with and without type 2 diabetes was performed according to the recommendations established by the Declaration of Helsinki and approved by the Ethics Committee of the Hospital de Clínicas de Porto Alegre (\# 150068).

Were included patients with type 2 diabetes (T2D) older than 60 years, with up to 48 hours of hospital admission, who agreed to participate in the study and signed the consent form. Were excluded patients with any mental decline or advanced motor sequalae; those who were treated at the Intensive Care Unit, and those who were in hospital for less than two days. The medical record was consulted for general information.

The body composition, and biochemical parameters (albumin) were evaluated in admission. Were performed the body circumferences: Calf circunferemce (CC), mid-arm circumference (MAC) and waist circumference (WC) using a metric tape. The height and the weight wrere measured for calculation body mass índex (BMI).

The patients' nutritional status was evaluated in the admission through the Mini Nutritional Assessment (MNA) and by Subjetive global assessment (SGA). The patients were classified according to the cut points by MNA: normal nutrition 24 to 30 points, risk of malnutrition with 17 to 23.5 points and malnutrition $<17$ points ${ }^{11}$ and by SGA those who obtained SGA-A were considered with normal nutrition, ASG-B moderate malnutrition and ASG-C with severe malnutrition. ${ }^{10}$

To evaluate the independence level, the Instrumental Activities of Daily Living test (IADL) ${ }^{17}$ was performed. The IADL is a scale that assesses eight tasks providing information about functional skills necessary to live independently in the community.

The APMT was performed according to proposed technique per Lameu et $\mathrm{al}^{21}$ : The average of 3 measurements of the dominant hand was considered as the average adductor muscle thickness. The APMT was considered as < or equal $18 \mathrm{~mm}$ for men and $<$ or equal $16 \mathrm{~mm}$ for women as indicator of muscle depletion and malnutrition. These 
values refer to the 5th percentile, proposed in a previous study that described cutoffs, stratified by sex, for healthy adults and older people. ${ }^{22}$ Therefore, we have used APMT lower $5^{\text {th }}$ percentile $(\mathrm{APMT}<\mathrm{p} 5)$ as a group of risk.

Survival data were consulted via telephone contact with all participants. The calls were made 30 days after hospital discharge and every 3 months until completing 12, 24 and 48 months. All death events were confirmed using the local death record database. The period from the first investigation to the date of death was recorded for participants who died during followup, the same was performed for all the other participants. The severity of comorbid diseases was recorded and scored according to Charlson comorbidity index (CCI) and was calculated according to the scoring system established by Charlson et al. ${ }^{23}$.

\section{Statistical Analysis}

All variables had normality assessed by Kolmogorov-Smirnov test, the results were described as average and standard deviation or median and interquartile range (IQR). Categorical variables were reported as frequencies. $\mathrm{T}$ test for independent variables for parametric variables or Mann Whitney for non-parametric variables were performed, chi-square test for categorical variables.

Kaplan Meier curves were performed to assess the impact of malnutrition or anthropometric variables on mortality. The differences between the curves were evaluated by the log-rank test. The mortality time was counted in months, considering the date of the first admission until the date of death. Univariate and multivariate Cox proportional-hazard models were applied to calculate the hazard ratio (HR) and 95\% confidence interval (CI). Significant covariates identified in the univariate Cox models (P $<0.20)$ were included in the multivariate Cox model. The variables that were included in the multivariate analysis were: age, sex, level of independence, MNA, CC, MAC and Charlson index $>2$ scores.

We used the Receiver Operating Characteristic (ROC) to determine whether the anthropometric variables and MAN correlated with mortality. The sample calculation was based on previous study ${ }^{39}$ we would need 518 patients, 259 with T2D and 259 without T2D. We increased the sample to 610 patients, predicting a possible loss of follow-up of around $15 \%$. This study showed that patients with T2D had 
a 3-fold higher mortality than those without T2D. The estimated power was $90 \%$ with na alpha error of $5 \%, \mathrm{p}<0.05$. All statistical analyzes were performed in the SPSS program version 18 (SPSS Inc. Chicago,IL, USA)

\section{Results}

The characteristics overall at baseline were described in Table 1. There were 113 (36.3\%) deaths in the follow-up period. Were included 311 patients with average age 73.7 $\pm 6.34,51 \%$ were females, $72 \%$ Caucasian and $84.9 \%$ sedentary. Neoplasia and hypertension were present in $69(25.9 \%)$ and 232 (75.3\%) respectively. The median length of stay was 14 (9-24) days. Nutritional status evaluated according to BMI identified 54.5\% ( $\mathrm{n}=168)$ were overweight, for other hand the MAN identified $45.7 \%$ of patients were at risk of malnutrition and $37.7 \%$ malnutrition and the SGA identify $61.7 \%$ $(\mathrm{n}=192)$ presented normal nutrition in admission.

Among those who died, the prevalence of malnutrition by MNA and ASG in admission was $24.3 \%(\mathrm{n}=28)$ and $7.2 \%(\mathrm{n}=10)$, respectively. Furthermore, presented lower CC (32.84 \pm 3.14 vs. $35.89 \pm 3.75 ; \mathrm{p}=0.019)$ and lower APMT $(9.08 \pm 3.52$ vs. $12.01 \pm 4.38 ; \mathrm{p}=0.001$ ) when compared with patients alive

Univariate analysis showed independent association between malnutrition (MAN and SGA), calf circumference ( $<33 \mathrm{~cm}$ for woman; $<34 \mathrm{~cm}$ for man), adductor pollicis muscle thickness $(<\mathrm{P} 5), \mathrm{CCI}$ and mortality after hospital discharge. In this sample, there was no association between mortality and BMI, MAC, abdominal circumference, arterial hypertension and IADL (Graph 1).

Multivariate analyzes post discharge mortality were described in Table 2. In model 1, with adjustments, malnutrition patients, with APMT less than the 5th percentile and WC (less than $33 \mathrm{~cm}$ for women, $34 \mathrm{~cm}$ for men) had a higher risk of post-discharge mortality. In model 2, both maintained an association with mortality after discharge.

In a combined model, we evaluated MNA and APMT and both remained associated with mortality after adjustment, as well as the coexistence of both (APMT + malnutrition).

However, when evaluating APMT and CC in the same model, only APMT <5th percentile increased the risk of mortality. 
The subjective global assessment and albumin were not significant in this sample of patients.

Survival curves the MNA and APMT are presented in Fig. 1A and 1B. The survival curves were statistically different by the log-rank test $(p=0.030$ and $p=0.002)$, indicating that patients with diabetes plus malnutrition or APMT $<$ P5 had a higher risk of mortality when compared to older patients with normal nutrition and with APMT >P5. The prediction power calculated by the area below the ROC curve was statistically significant for MAN (0.591) and APMT (0.671), as shown in Graph 2.

\section{Discussion}

This study investigated the relationship between anthropometric variables, MNA, SGA and mortality after 4 years hospital discharge within in older patients with T2D. We found that older malnutrition patients with reduced calf circumference $(<33 \mathrm{~cm}$ for women and $<34 \mathrm{~cm}$ for men) or with adductor pollicis muscle thickness below the 5th percentile had a higher risk of mortality after hospital discharge. In addition, patients with malnutrition plus APMT $<5$ had a $40 \%$ risk of mortality after discharge.

These results demonstrate to the importance of assessing older patients with T2D in the hospital environment more broadly. Hospital malnutrition is still a prevalent theme, and despite the numerous negative outcomes, it is still often neglected ${ }^{24}$. In this sample $168(54.5 \%)$ were overweight and had elevated waist circumference $(103.2 \mathrm{~cm} \pm 13.2$ for men and $100.7 \pm 14.8$ for women), however, 136 (44\%) had low WC, 275 (88.4\%) APMT below the 5th percentile and 142 (45.7\%) with nutritional risk.

This was the first study to evaluate the relationship between APMT and mortality in older patients with T2D. It is known that patients with T2D have lower muscle mass when compared to patients without $\mathrm{DM}^{25}$ but most studies assess the relationship between overweight and obesity with negative outcomes without assessing muscle mass. In our data, patients with T2D were overweight, evaluated by the BMI, and also APMT <p5 (median $11 \mathrm{~mm}$ ), but there was no relation between overweight and mortality. On the other hand, when evaluated by MNA, they presented $17.9 \%$ of malnutrition, being associated with post-discharge mortality

The APMT has been evaluated in different clinical situations ${ }^{26-29}$ and in the healthy population. ${ }^{22}$ Regarding the APMT association and mortality, previous studies ${ }^{27-}$ ${ }^{30}$ associated the lower APMT with mortality under different scenarios. Caparossi et. $\mathrm{al}^{29}$ 
in his study with surgical patients showed that among patients who died, APMT values were significantly lower $(11.4 \pm 4.1$ in the right hand and $11.2 \pm 3.9$ in the left $\mathrm{p}=0.03)$. Likewise, Bragnolo et al. ${ }^{27}$ showed that postoperative mortality was $25 \%$ higher in patients with APMT below the cut-off point considered for dominant hand in the older patients $<12.2 \mathrm{~mm}$ (women) and $<14.4 \mathrm{~mm}$ for men and Ghorabi et.al ${ }^{30}$ in patients from intensive care unit, $11.12 \pm 2 \mathrm{~mm}$ in the patients who died and $16.7 \pm 2.2 \mathrm{~mm}$ in those who survived $(\mathrm{P}=.05)$.

In our sample, $43.7 \%$ of patients had, at the time of admission, the calf circumference below the cohort point. In last years, there was an increase in publications with calf circumference to in different populations for different outcomes, mainly because it is a good marker of muscle mass in older patients ${ }^{31}$, has an association with sarcopenia ${ }^{32}$, is a predictor of readmission ${ }^{33}$ and mortality. ${ }^{34}$ Because it is an easy-to-measure and low-cost measure, it can be part of the routine assessment of hospitalized patients.

The MNA it is a tool that better detects malnutrition or the risk of malnutrition in hospitalized older people than BMI. ${ }^{11}$ Other studies evaluated the relationship between MNA and mortality in different clinical situations. Joaquin $\mathrm{C}$ et. $\mathrm{al}^{35}$ in a study of cohort, malnutrition was an independent predictor of 2-year all-cause death in 151 outpatients with heart failure (OR:4.56 CI95\% 1.55-13.4). Similarly, Van Wilssen J et al. ${ }^{36}$ showed the association between the preoperative MNA score and mortality after surgery for hip fractures in 226 older patients, with mortality in hospital and 1-year mortality of $27 \%$ and $46 \%$ in malnutrition patients, respectively.

The dependence level also showed an evident association with mortality after 4 years of hospital discharge. The more dependent older patients (with less points in the IADL) had a higher mortality rate when compared to the independent patients; the association between IADL and mortality already described for other authors. ${ }^{37,37}$

As shortcomings, the APMT measurement was performed only once, 48 hours after admission, and it was not possible to assess whether the patients further reduced the thickness during hospitalization. As strength of our study, we highlight the prospective design, as well as the significant number of patients evaluated for a significant time after hospital discharge. It is becoming increasingly important to include the assessment of muscle mass and functionality in the older individual as a complementary way to nutritional assessment. 


\section{Conclusions}

In fact, the nutritional status during the hospitalization is important and can be a risk factor for other problems, often not related to the main reason for hospitalization. Thus, body changes in the older patient with type 2 diabetes can mask muscle and functional loss. Despite technological advances in body assessment methods, anthropometrics assessments, such as the circumference of the calf and the thickness of the adductor pollicis muscle, are still a safe, low-cost and validated method that can be used in combination with other tools to identify body changes in older patients.

\section{Availability of data and materials}

All data generated or analyzed during this study are included in this published article.

\section{Competing interests}

The authors declare that they have no competing interests.

\section{Funding}

Financial support was provided by Research and Events Support Fund at Hospital de Clınicas de Porto Alegre (FIPE-HCPA) and PROEX-CAPES.

\section{Authors' contributions}

Beretta MV and Rodrigues TC were responsible for the study concept desig, data analysis, interpretation of findings and drafted the manuscript Feldman JV and Silva $\mathrm{CN}$ contributed to data acquisition. All authors read and approved the final manuscript.

\section{Acknowledgment}

We would like to thank all the hospitalized patients who agreed to participate in this study, to students of scientific initiation Juliane Feldman and Camila Nery. To Instituto Nacional de Desenvolvimento Cientıfico e Tecnologico (CNPq). 


\section{Declarations}

Ethics approval and consent to participate: This project follows the recommendations established by the Declaration of Helsinki and was approved by the Ethics Committee of Hospital de Clínicas de Porto Alegre under number: 15008.

Consent for publication: Not applicable in this section. 


\section{References}

1. Castro Sales MV, da Silva TJA, Gil Jr JA, Jacob Filho W. Adverse events of hospitalization for the elderly patient. Geriatria \& Gerontologia. 2010;4(4):238246

2. Inouye SK. Delirium in older persons. N Engl J Med. 2006:354 (11):1157-65.

3. Waitzberg DL, Caiaffa WT, Correia MI. Hospital Malnutrition: the Brazilian national survey (IBRANUTRI): a study of 4000 patients. Nutrition. 2001;17:57380

4. Beretta MV, Filho FFD, Eccel FR et al. Sarcopenia and Type 2 diabetes mellitus as predictors of 2-year mortality after hospital discharge in a cohort of hospitalized older adults. Diabetes Research and Clin Practice 1 59(2020 ) 107969

5. Gong-Xiang Liu, Yan Chen, Ying-Xue Yang, Kun Yang, Jin Liang, Shuang Wang and Hua-Tian Gan. Pilot study of the Mini Nutritional Assessment on predicting outcomes in older adults with type 2 diabetes. Geriatr Gerontol Int 2017; Dec;17(12):2485-2492

6. Sanz Paris A, Garcia JM, Gomez-Candela C, Burgos R,Martin A, Matia P. Malnutrition prevalence in hospitalized elderly diabetic patients. Nutricion hospitalaria $2013 ; 28: 592-599$

7. Sayer, A. A. et al. Type 2 diabetes, muscle strength, and impaired physical function: the tip of the iceberg? Diabetes Care. 28,2005-2541-2542

8. Cetinus, E., Buyukbese, M. A., Uzel, M., Ekerbicer, H. \& Karaoguz, A. Hand grip strength in patients with type 2 diabetesmellitus. Diabetes Res Clin Pract. 702005, 278-286

9. Seok Won Park,Bret H. Goodpaster, Elsa S. Strotmeyer et. Al Decreased Muscle Strength and Quality in Older Adults With Type 2 Diabetes; Diabetes 2006; Jun;55(6):1813-8

10. Detsky AS, McLaughlin JR, Baker JP, Johnston N, Whittaker S, Mendelson RA, et al. What is subjective global assessment of nutritional status? JPEN J Parenter Enteral Nutr 1987; 11:8-13

11. Guigoz Y, Vellas B, Garry PJ. Assessing the nutritional status of the elderly: The Mini Nutritional Assessment as part of the geriatric evaluation. Nutr Rev. 1996;54(1 Pt 2):S59-65 
12. Frisancho RA. New norms of upper limb fat and muscle areas for assessment of nutritional status. Am J Clin Nutr. 1974;34:2540-4

13. M Bonnefoy, M Jauffret, T Kostka, J F Jusot. Usefulness of calf circumference measurement in assessing the nutritional state of hospitalized elderly people. Gerontology.May-Jun 2002;48(3):162-9

14. Lameu EB, Gerude MF, Lima A. Original research adductor policis muscle: a new anthropometric parameter. 2004;59(2):57-62

15. Covinsky KE, Martin GE, Beyth RJ, Justice AC, Sehgal AR, Landefeld CS. The relationship between clinical assessments of nutritional status and adverse outcomes in older hospitalized medical patients. J Am Geriatr Soc 1999;47:5328.

16. Keith JN. Bedside nutrition assessment past, present, and future: a review of the Subjective Global Assessment. Nutr Clin Pract. 2008;23(4):410-6. doi: $10.1177 / 0884533608321215$.

17. Silvio Buscemi, John A. Batsis, Gaspare Parrinello et al. Nutritional predictors of mortality after discharge in elderly patients on a medical Ward. Eur J Clin Invest 2016; 46 (7): 609-618

18. Chien-Hsiang Weng, Chia-Ping Tien, Chia-Ing Liet. Al. Mid-upper arm circumference, calf circumference and mortality in Chinese long-term care facility residents: a prospective cohort study. BMJ Open 2018 May 9;8(5):e020485

19. Tsai AC, Chang TL. The effectivenesss of BMI, calf circumference and mid-arm circumference in predicting subsequent mortality risk in elderly Taiwanese. Br J Nutr. 2011;105(2):275-81.

20. Shu-Chuan Ho, Jiun-Yi Wang, Han-Pin Kuo et al. Mid-arm and calf circumferences are stronger mortality predictors than body mass index for patients with chronic obstructive pulmonary disease. Int J Chron Obstruct Pulmon Dis 2016 Aug 31;11:2075-80.

21. Lawton MP BM. Assessment of older people: self-maintaining and instrumental activities of daily living. Gerontologist. 1969;9(3):179-186.

22. Gonzalez MC, Duarte RR, Budiziareck MB. Adductor pollicis muscle: Reference values of its thickness in a healthy population. Clin Nutr. 2010 
23. Charlson ME, Pompei P, Ales KL MC. A new method of classifying prognostic comorbidity in longitudinal studies: development and validation. $\mathrm{j}$ chronic dis. 1987; 40:373-383.

24. Toledo DO, Piovacari SMF, Horie LM, De Matos LBN, Castro MG, Ceniccola GD et al. Campanha "Diga não à desnutrição": 11 passos importantes para combater a desnutrição hospitar. Braspen. 018;33(1):86-100.

25. Kim KS, Park KS, Kim MJ, Kim SK, Cho YW. Type 2 diabetes is associated with low muscle mass in older adults. Geriatr Gerontol Int 2014; 14 (Suppl. 1): 115121

26. Freitas BJSA, Mesquita LC, Teive NJV, Souza SR. Classical Anthropometry and the Adductor Pollicis Muscle to Determine the Nutritional Prognosis in Patients with Cancer. Rev Bras Cancerol. 2010;56(4):415-422.

27. Bragagnolo R, Caporossi FS, Dock-Nascimento DB, Aguilar-Nascimento J eduardo de. Espessura do músculo adutor do polegar: um método rápido e confiável na avaliação nutricional de pacientes cirúrgicos. Rev Col Bras Cir. 2010;36(5):371-376.

28. Katarina Papera Valente, Betullya Lucas Almeida, Thailiny Ricati Lazzarini et al. Association of Adductor Pollicis Muscle Thickness and Handgrip Strength with nutritional status in cancer patients. PLoS One 2019 Aug 2;14(8):e0220334

29. Caporossi FS, Caporossi C, Dock-nascimento DB. Measurement of the thickness of the adductor pollicis muscle as a predictor of outcome in critically ill patients. Nutr Hosp. 2012;27(2):490-495.

30. Ghorabi S, Ardehali H, Amiri Z, Vahdat Shariatpanahi Z. Association of the Adductor Pollicis Muscle Thickness with Clinical Outcomes in Intensive Care Unit Patients. Nutr Clin Pract. 2016;31(4):523-526

31. Valéria PagottoI, Kássylla Ferreira dos SantosII, Suelen Gomes Malaquias et al. Calf circumference: clinical validation for evaluation of muscle mass in the elderly. Rev Bras Enferm [Internet]. 2018;71(2):343-50.

32. Ryoko Kawakami, Haruka Murakami, Kiyoshi Sanada et al. Calf circumference as a surrogate marker of muscle mass for diagnosing sarcopenia in Japanese men and women. Geriatr Gerontol Int 2015 Aug;15(8):969-76. 
33. Frühauf IR,Sedrez JHK,Dall'Aqua EJF, Gonzalez MC.. Calf Circumference: A Marker of Muscle Mass as a Predictor of Hospital Readmission. JPEN J Parenter Enteral Nutr. 2018 May 15.

34. Jonathan F Easton, Christopher R Stephens, Heriberto Román-Sicilia et al. Anthropometric measurements and mortality in frail older adults. Exp Gerontol2018 Sep;110:61-66

35. Joaquín C, Puig R, Gastelurrutia P, Lupón J, de Antonio M, Domingo M, Moliner P, Zamora E, Martin M, Alonso N, Puig-Domingo M B-GA. Mini nutritional assessment is a better predictor of mortality than subjective global assessment

36. van Wissen J, Stijn V, Doodeman H, Houdijk A. Mini Nutritional Assessment and Mortality after Hip Fracture Surgery in the Elderly. J Nutr Heal Aging. 2016; 9:964-968.

37. Millán-Calenti J, J T, Pita-Fernández, S González-Abraldes I, Lorenzo T, Fernández-Arruty TMA. Prevalence of functional disability in activities of daily living (ADL), instrumental activities of daily living (IADL) and associated factors, as predictors of morbidity and mortality. Arch Gerontol Geriatr. 2010; 3:306-310.

38. X. Lo A, Donnelly JP, McGwin Jr G, Bittner V, Ahmed A, Brown CJ. Impact of Gait Speed and Instrumental Activities of Daily Living on All-Cause Mortality in Adults $\geq 65$ Years of Age with Heart Failure. Am J Cardiol. 2015; 6:797-801

39. Wu MC, Lee WJ, Tschen SM, et al. Predictors of mortality in hospitalized diabetic patients: A 7-year prospective study. Diabetes Res. Clin. Pract. 2008;80:449-54 
Table 1.Baseline clinical and nutrition characteristics of older patients with T2D

\begin{tabular}{|c|c|c|c|c|}
\hline & All patients $(n=311)$ & Alive $(n=198)$ & $\operatorname{Dead}(n=113)$ & $\mathbf{P}^{*}$ \\
\hline Age (years) & $73.7 \pm 6.34$ & $74.85 \pm 6.60$ & $73.10 \pm 6.11$ & 0.019 \\
\hline Gender (Women) & $159(51)$ & $89(45)$ & $70(62)$ & 0.005 \\
\hline Caucasian & $224(72)$ & $143(72.2)$ & $81(71.7)$ & 0.432 \\
\hline Elementary School & $201(64.6)$ & $129(65)$ & $72(63.7)$ & 0.369 \\
\hline Smokers n $(\%)$ & $45(14.5)$ & $34(17.2)$ & $11(9.7)$ & 0.128 \\
\hline Alcoholics n (\%) & $43(13.8)$ & $32(16.2)$ & $11(9.7)$ & 0.222 \\
\hline Sedentary n $(\%)$ & $264(84,9)$ & $169(8.4)$ & $95(84.1)$ & 0.744 \\
\hline Malignant neoplasm n (\%) & $69(25.9)$ & $30(18.1)$ & $39(39)$ & 0.001 \\
\hline SAH n $(\%)$ & $232(75.3)$ & $151(76.6)$ & $81(73)$ & 0.49 \\
\hline More than 5 drougs $\mathrm{n}(\%)$ & $114(36.7)$ & $80(40.4)$ & $34(30)$ & 0.087 \\
\hline IADL (dependent) n(\%) & $246(79)$ & $158(79.8)$ & $88(77.9)$ & 0.772 \\
\hline LOS (days) & $14(9-24)$ & $14(9-23)$ & $15(9-27)$ & $0.268 ¥$ \\
\hline $\mathrm{IMC}(\mathrm{kg} / \mathrm{m} 2)$ & $27.91 \pm 5.71$ & $27.88 \pm 5.08$ & $27.98 \pm 5.61$ & 0.87 \\
\hline Normal nutrition & $111(34.7)$ & $70(35.4)$ & $38(35.4)$ & \\
\hline malnutrition & $32(10.4)$ & $22(11.1)$ & $10(9.1)$ & 0.74 \\
\hline overweight & $168(54.5)$ & $106(53.5)$ & $62(56.4)$ & \\
\hline ASG (score) & & $18.07 \pm 2.41$ & $19.19 \pm 2.57$ & 0.18 \\
\hline Normal nutrition & $192(61.7)$ & $130(65.5)$ & $63(56.8)$ & \\
\hline moderate malnutrition & $104(33.4)$ & $64(32.5)$ & $40(36)$ & 0.039 \\
\hline malnutrition & $15(3.9)$ & $4(2.0)$ & $10(7.2)$ & \\
\hline MNA (score) & & $25.05 \pm 4.73$ & $23.55 \pm 4.61$ & 0.007 \\
\hline Normal nutrition & $111(35.7)$ & $82(41.1)$ & $30(27)$ & \\
\hline risk of malnutrition & $142(45.7)$ & $88(44.7)$ & $54(48.6)$ & 0.004 \\
\hline malnutrition & $58(37.7)$ & $28(14.2)$ & $29(24.3)$ & \\
\hline $\mathrm{AC}$ (men) & $103.2 \pm 13.21$ & $102.13 \pm 13.16$ & $103.65 \pm 13.27$ & 0.561 \\
\hline $\mathrm{AC}$ (woman) & $100.7 \pm 14.8$ & $100.03 \pm 14.91$ & $101.28 \pm 15.34$ & 0.628 \\
\hline Arm circumference $(\mathrm{cm})$ & $30.31 \pm 3.97$ & $30.47 \pm 3.76$ & $30.04 \pm 4.33$ & 0.36 \\
\hline Calf circumference $(\mathrm{cm})$ & $33.51 \pm 3.77$ & $35.89 \pm 3.75$ & $32.84 \pm 3.14$ & 0.019 \\
\hline$<33 \mathrm{~cm}$ woman; <34cm men) & & $78(39.4)$ & $58(52.3)$ & 0.020 \\
\hline AMPT (mm) & $10.60 \pm 4.21$ & $12.01 \pm 4.38$ & $9.08 \pm 3.52$ & 0.001 \\
\hline APMT $<$ P5 & $275(88.4)$ & $169(85.4)$ & $106(93.8)$ & 0.027 \\
\hline Albumin $(\mathrm{g} / \mathrm{dl})$ & $3.70 \pm 0.67$ & $3.75 \pm 0.64$ & $3.59 \pm 0.70$ & 0.04 \\
\hline
\end{tabular}

\section{Causes of hospitalization}

$\begin{array}{rc}\text { Cardiovascular } & 80(25) \\ \text { Neoplasias } & 50(16) \\ \text { Infectious diseases } & 98(18.8) \\ \text { Surgery } & 34(11) \\ \text { COPD } & 18(6.0) \\ \text { Death } \mathrm{n}(\%) & 113(36.3)\end{array}$

*Student’s t-test or Pearson chi-square test when appropriate. ¥ Mann-Whitney test. SAH: Systolic arterial hypertensionIADL: Instrumental Activity of Daily Living; LOS: length of stay; BMI: body mass index; SGA: subjective global assessment; MNA: mini nutrition assessment; CC: calf circumference; AC: abdominal circumference; APMT: adductor pollicis muscle tickness; COPD: Chronic obstructive pulmonary disease 
MNA (risk of malnutrition)

MNA(mainutrition)

Malnutrition + APMT $<$ P5

Calf circumference

Arm Circumference $(\mathrm{cm})$

Abdominal circumference $(\mathrm{cm}$

SGA (malnutrition)

BMI (malnutrition)

APMT $(<p 5)$

Age (years)

Gender

Albumin (g/dl)

SAH

IADL

Charkon Index

0,5

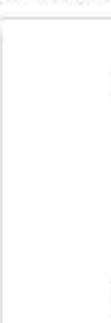
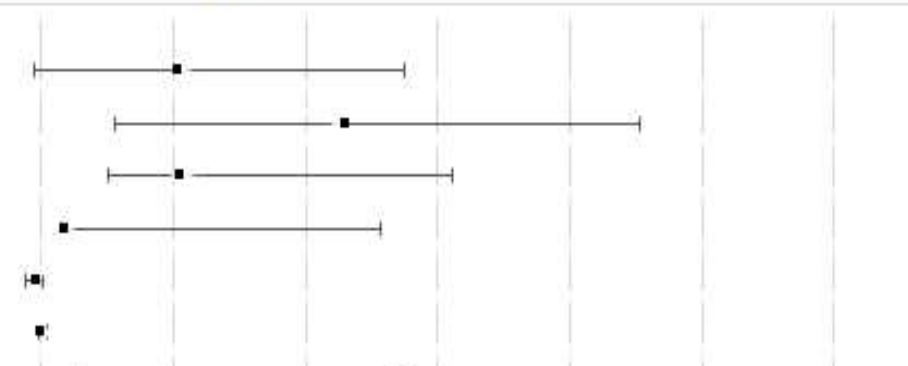

\footnotetext{
.
}

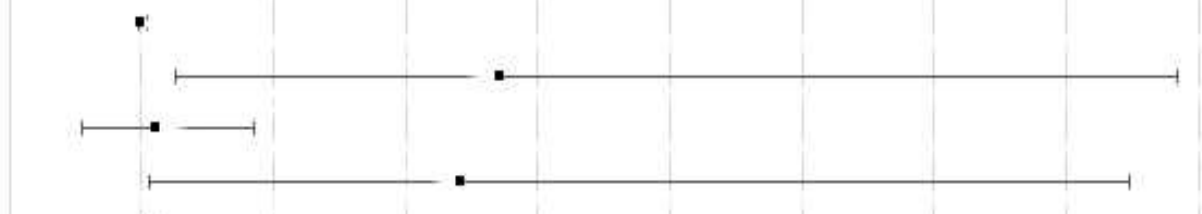

$1.52(0.97-2.37)$

$2.15(1.28-3.61)$

$1.52(1.25-2.54)$

$1.09(1.08-2.28)$

$0.97(0.94-1.01)$

$1.02(0.99-1.01)$

$2.36(1.13-4.92)$

$1.05(0.77-1.43)$

$2.20(1.02-4.74)$

$1.02(0.99-1.05)$

$1.48(1.01-2.19)$

$0.75(0.57-1.01)$

$1.21(0.78-1.82)$

$1.16(0,88-1.58)$

$1.16(1.04-1.29)$

OR: odds ratio; CI 95\%: confidence interval 95\%; MNA: mini nutrition assessment; APMT: adductor pollicis muscle thickness; SGA: subjective Global assessment; BMI: body mass index; SAH: systolic arterial hypertension, IADL: instrumental Activity of Daily Living

Table 2. Adjusted analysis of the relationship between nutritional markers and mortality

\begin{tabular}{|c|c|c|c|c|c|c|}
\hline MNA (risk) & $\begin{array}{c}\text { MNA } \\
\text { (malnutrition) }\end{array}$ & $\operatorname{APMT}(<\mathbf{p 5})$ & $\begin{array}{c}\text { APMT }(<p 5)+ \\
\text { malnutrition }\end{array}$ & $\begin{array}{c}\mathrm{CC}(<33 \mathrm{~cm} ;<34 \\
\mathrm{cm})\end{array}$ & $\begin{array}{c}\text { SGA } \\
\text { malnutrition }\end{array}$ & Albumin (g/dl) \\
\hline OR $(95 \%$ CI $)$ & OR $(95 \%$ CI $)$ & OR $(95 \%$ CI $)$ & OR $(95 \%$ CI $)$ & OR $(95 \%$ CI $)$ & OR $(95 \%$ CI $)$ & OR $(95 \%$ CI $)$ \\
\hline $1.45(0.92-2.27)$ & $2.02(1.19-3.43)$ & $2.37(1.10-5.11)$ & & $1.48(1.15-2.89)$ & $2.04(0.96-4.31)$ & $0.79(0.59-1.07)$ \\
\hline $1.42(0.91-2.23)$ & $1.92(1.13-3.24)$ & $2.33(1.08-5.03)$ & $1.40(1.04-1.30)$ & $1.03(1.00-1.06)$ & & \\
\hline \multirow[t]{2}{*}{$1.41(0.90-2.20)$} & $1.78(1.05-3.03)$ & $2.91(1.18-7.17)$ & & & & \\
\hline & & $2.83(1.14-7.02)$ & & $1.30(0.88-1.90)$ & & \\
\hline
\end{tabular}

Model 1: adjusted for age and gender; Model 2:Adjusted for age, gender, CCI; Combined model: analyzes adjusted for the same variables as model 1 and model 2, but performed with the combination: MNA and APMT or CC and APMT

OR: odds ratio; CI 95\%: confidence interval; MNA: mini nutrition assessment; CCI: Charlson comorbidity index : APMT: adductor pollicis muscle tickness; CC: calf circumference 
Figure 1A. Relationship between adductor pollicis muscle thickness and mortality

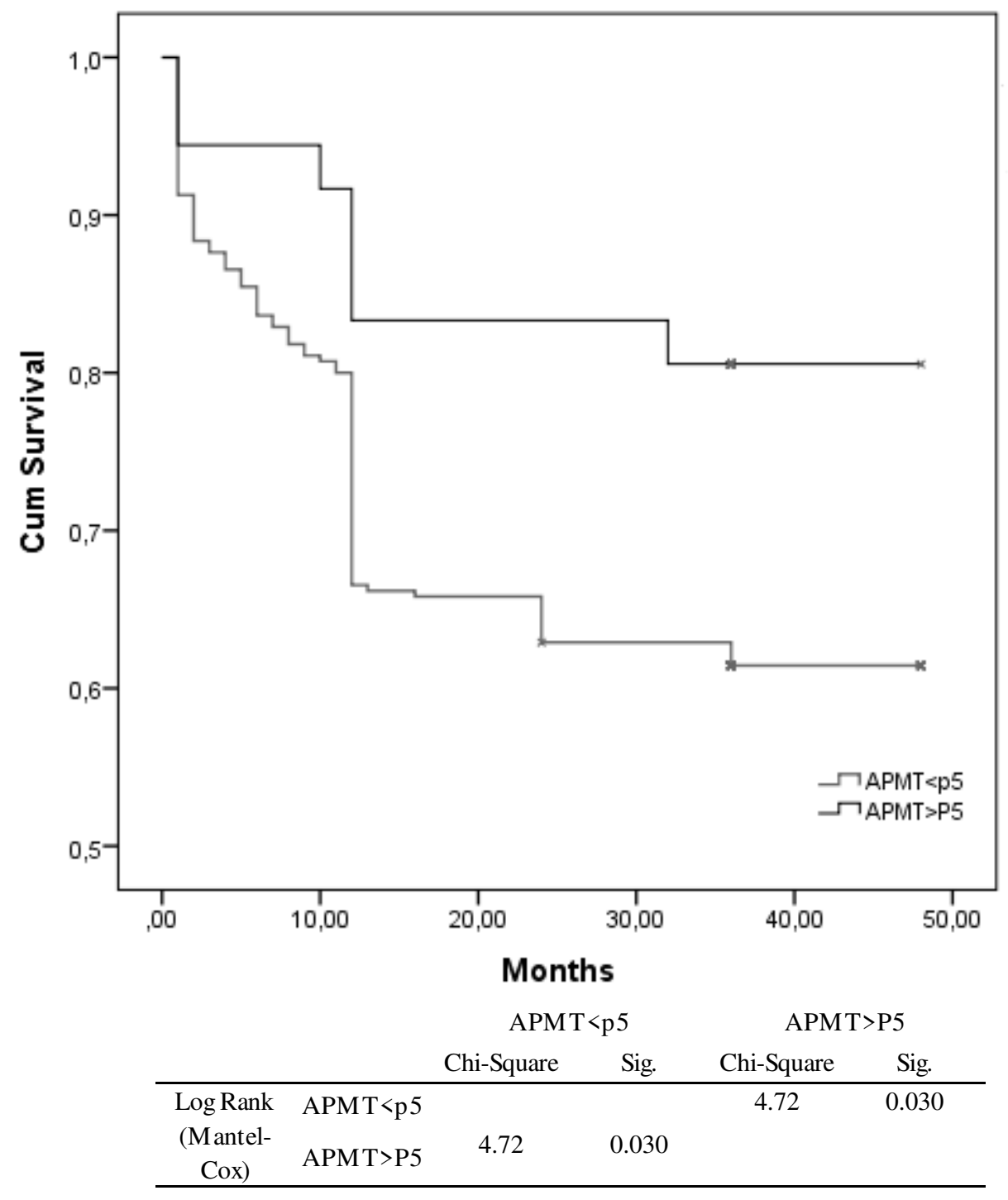


Figure 1B. Relationship between mini assessment nutrition and mortality

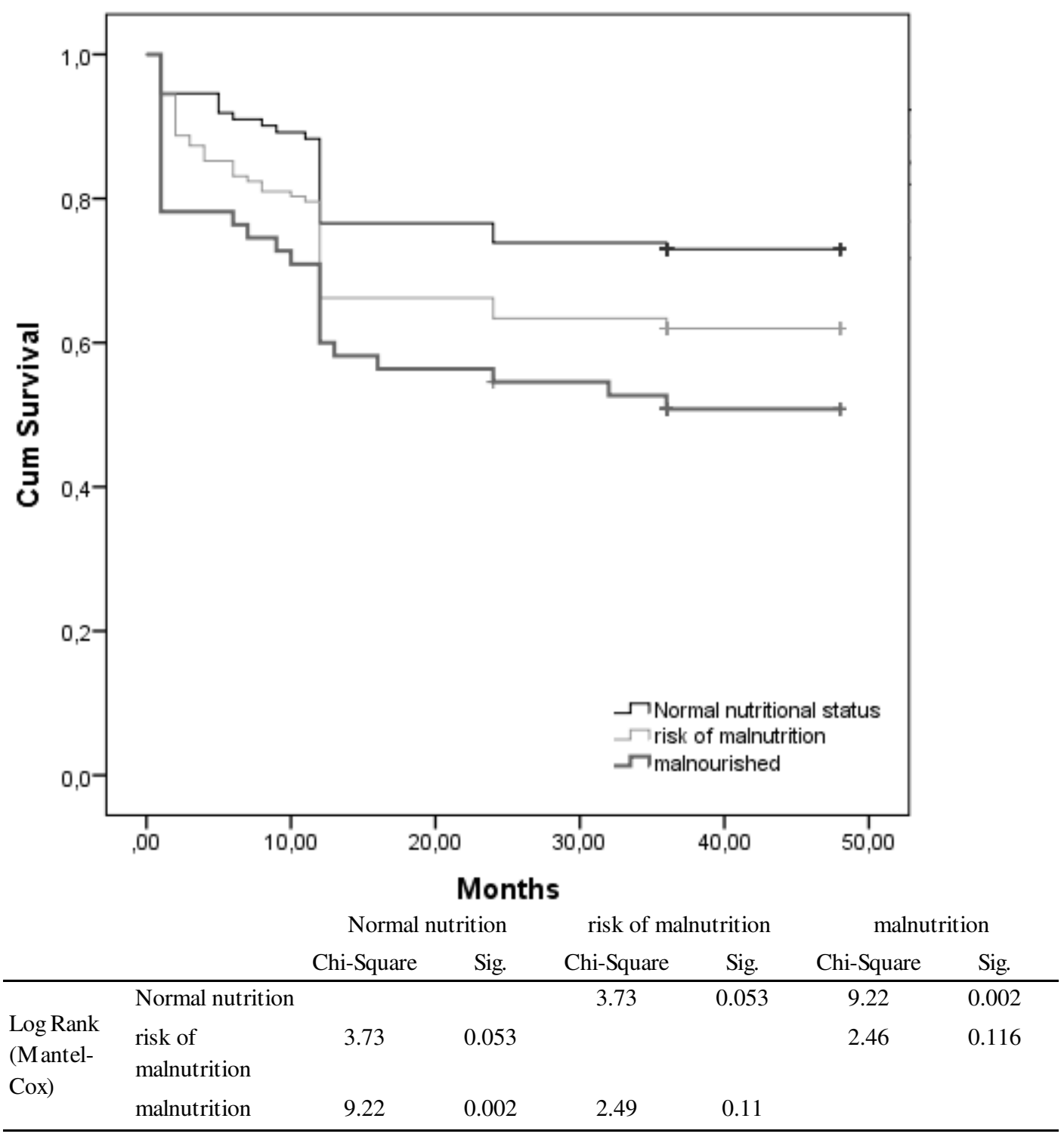


Graph 2. ROC curve of MNA and APMT

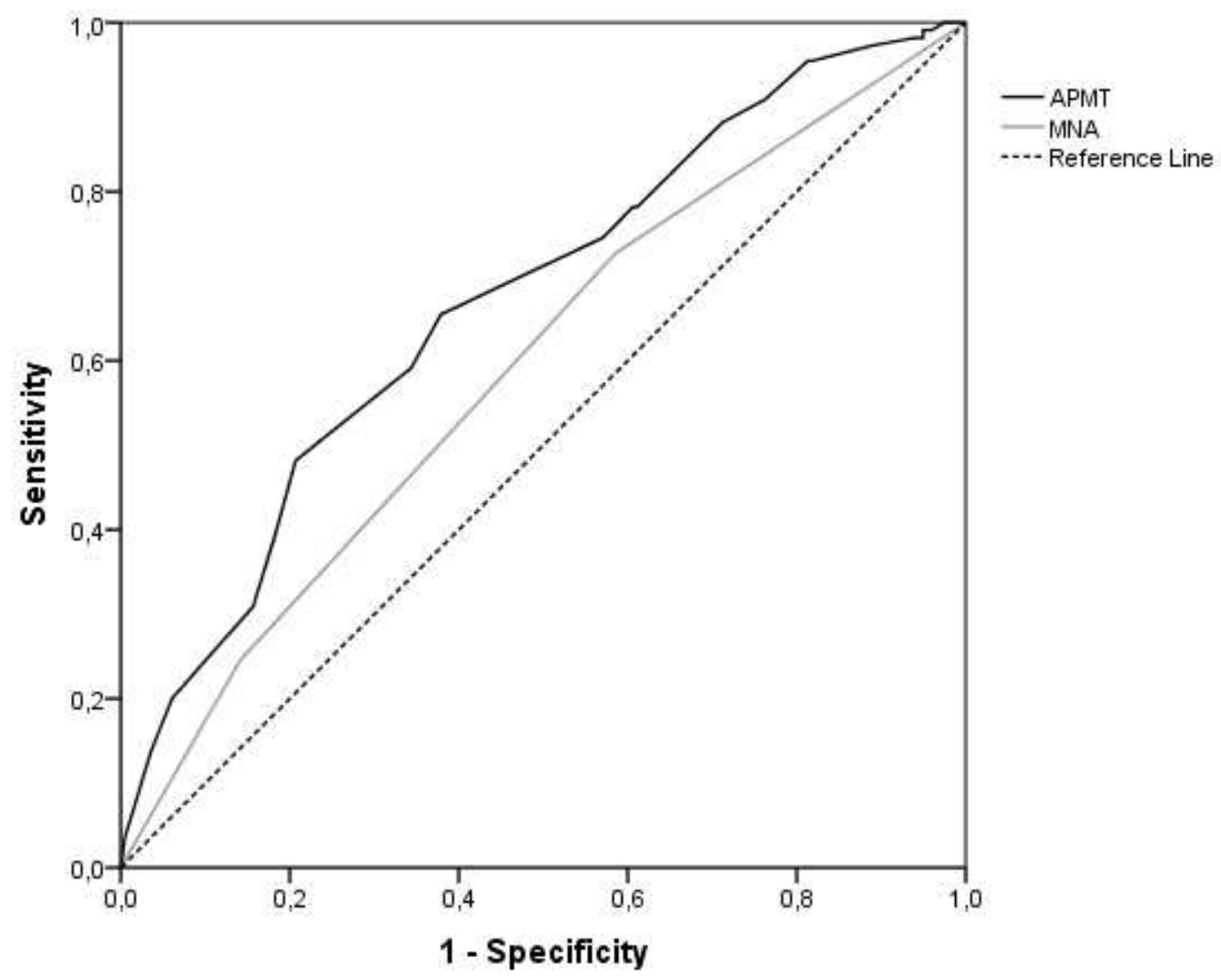

Area Under the Curve

\begin{tabular}{lcrrr}
\hline & & & \multicolumn{2}{c}{ Confidence Interval } \\
Test Result & & Asymptotic & \multicolumn{2}{l}{$\begin{array}{l}\text { Lower } \\
\text { Upper }\end{array}$} \\
Variable(s) & Area & Sig. $^{\text {b }}$ & Bound & Bound \\
\hline APMT & 0.671 & 0.000 & 0.608 & 0.733 \\
MNA & 0.591 & 0.008 & 0.525 & 0.657 \\
\hline
\end{tabular}

a. Under the nonparametric assumption

b. Null hypothesis: true area $=0.5$ 
Figures

Graphic 1. Unadjusted analysis between nutritional markers and mortality

OR $95 \%$ C

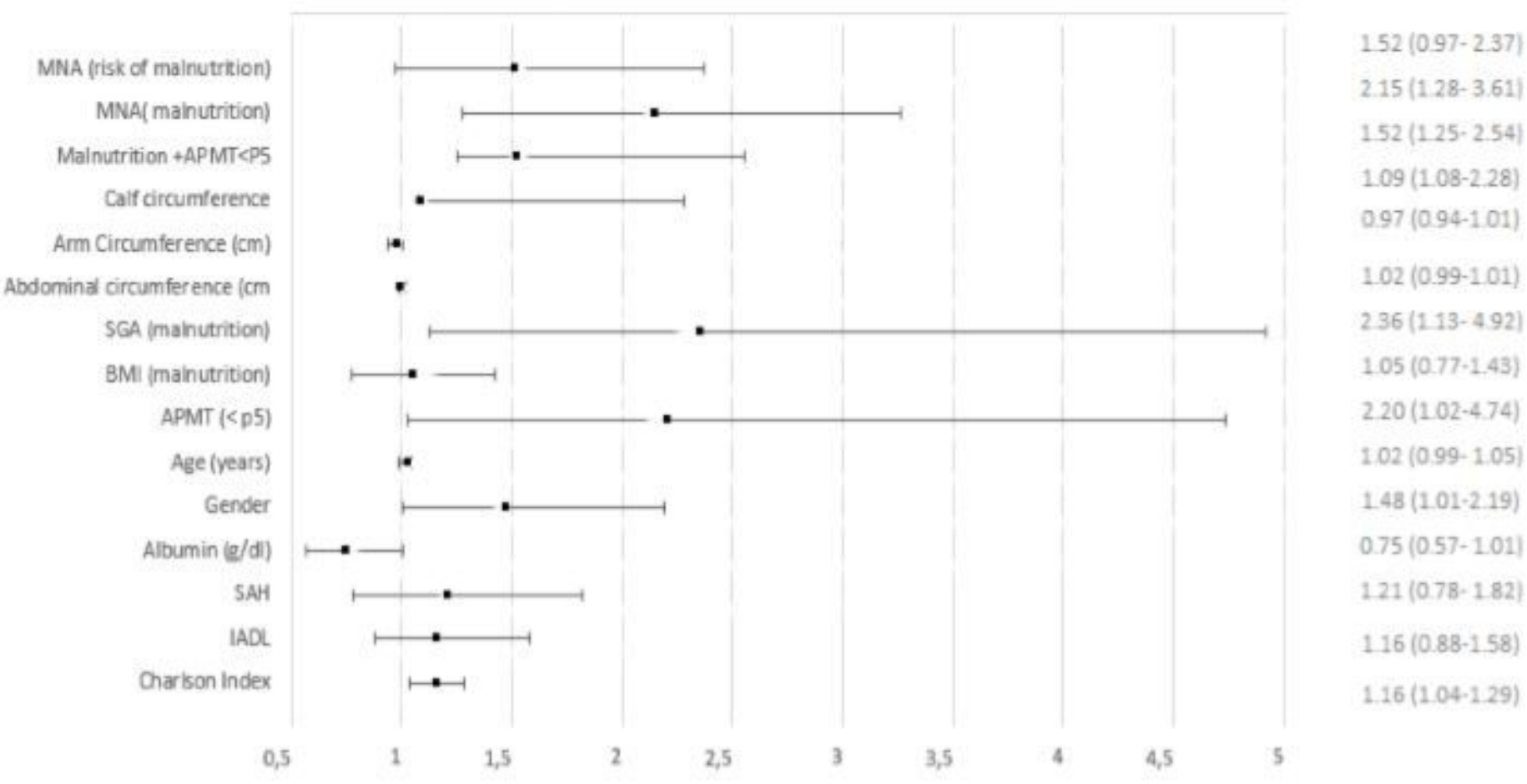

OR: odds ratio; CI 95\%: confidence interval 95\%; MNA: mini nutrition assessment; APMT: adductor pollicis muscle thicloness; SGA: subjective Global assessment; BMI: body mass index; SAH: systolic arterial hypertension, IADL: instrumental Activity of Daily Living

\section{Figure 1}

Unadjusted analysis between nutritional markers and mortality 


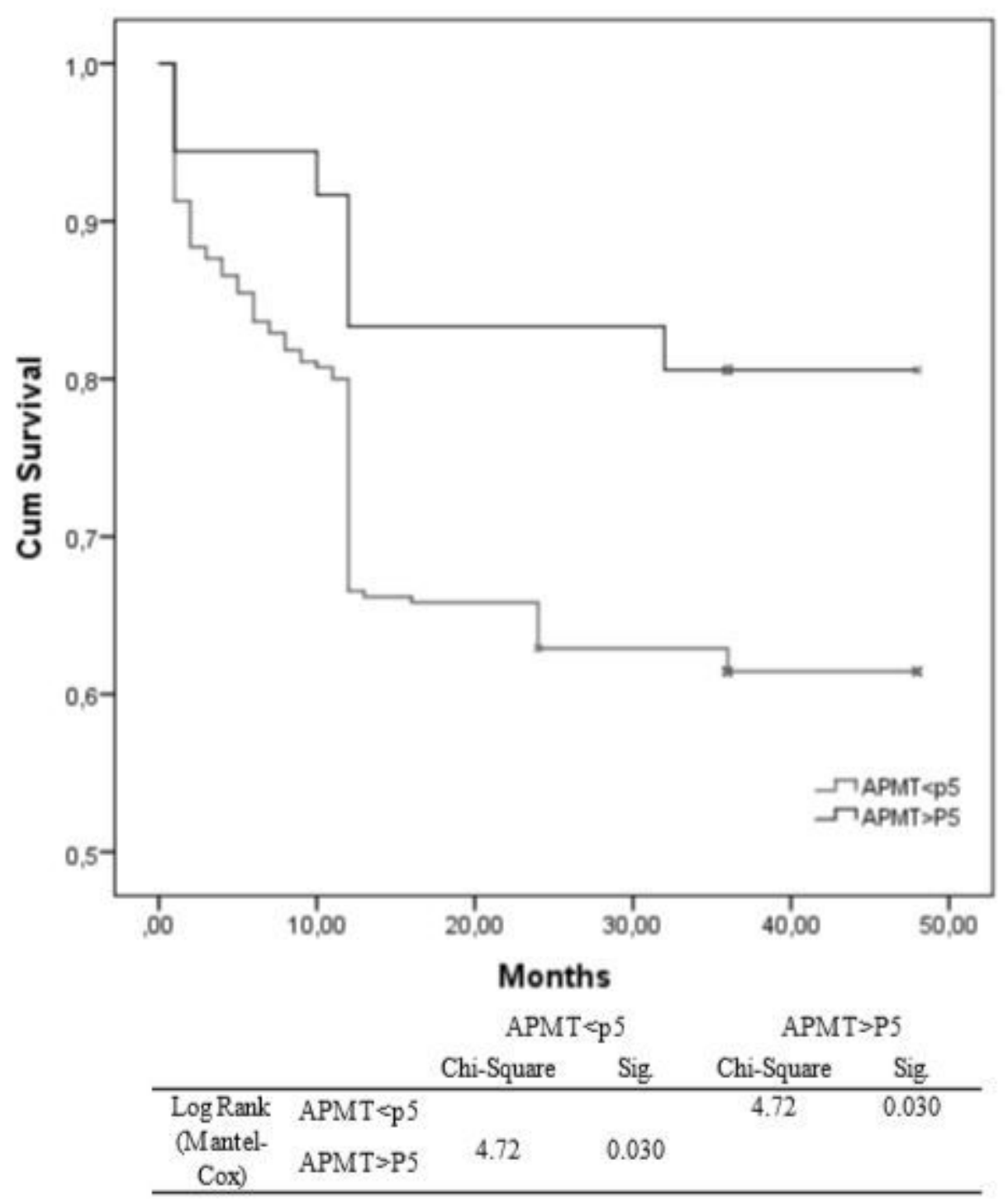

Figure 2

Relationship between adductor pollicis muscle thickness and mortality 


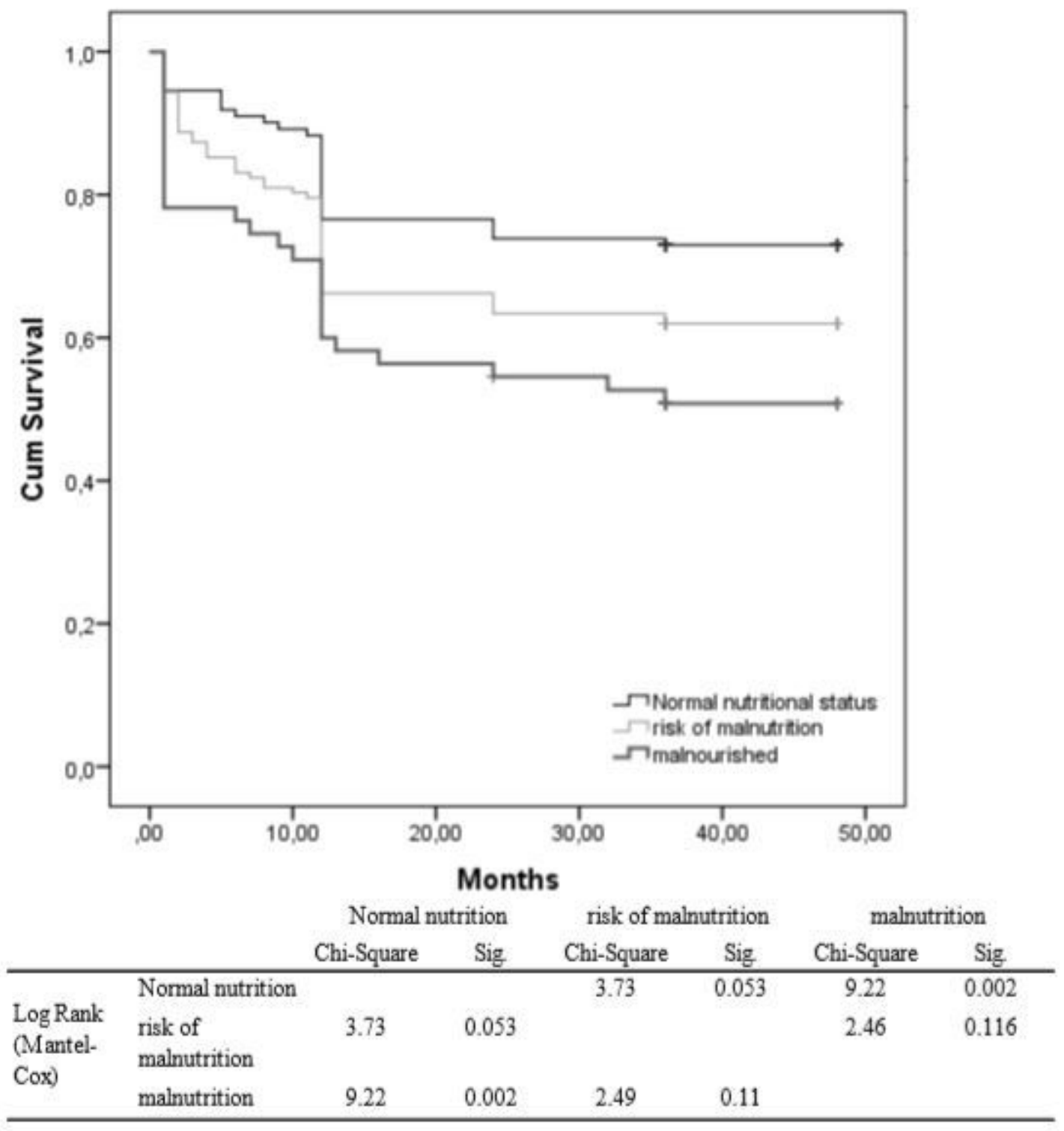

\section{Figure 3}

Relationship between mini assessment nutrition and mortality 


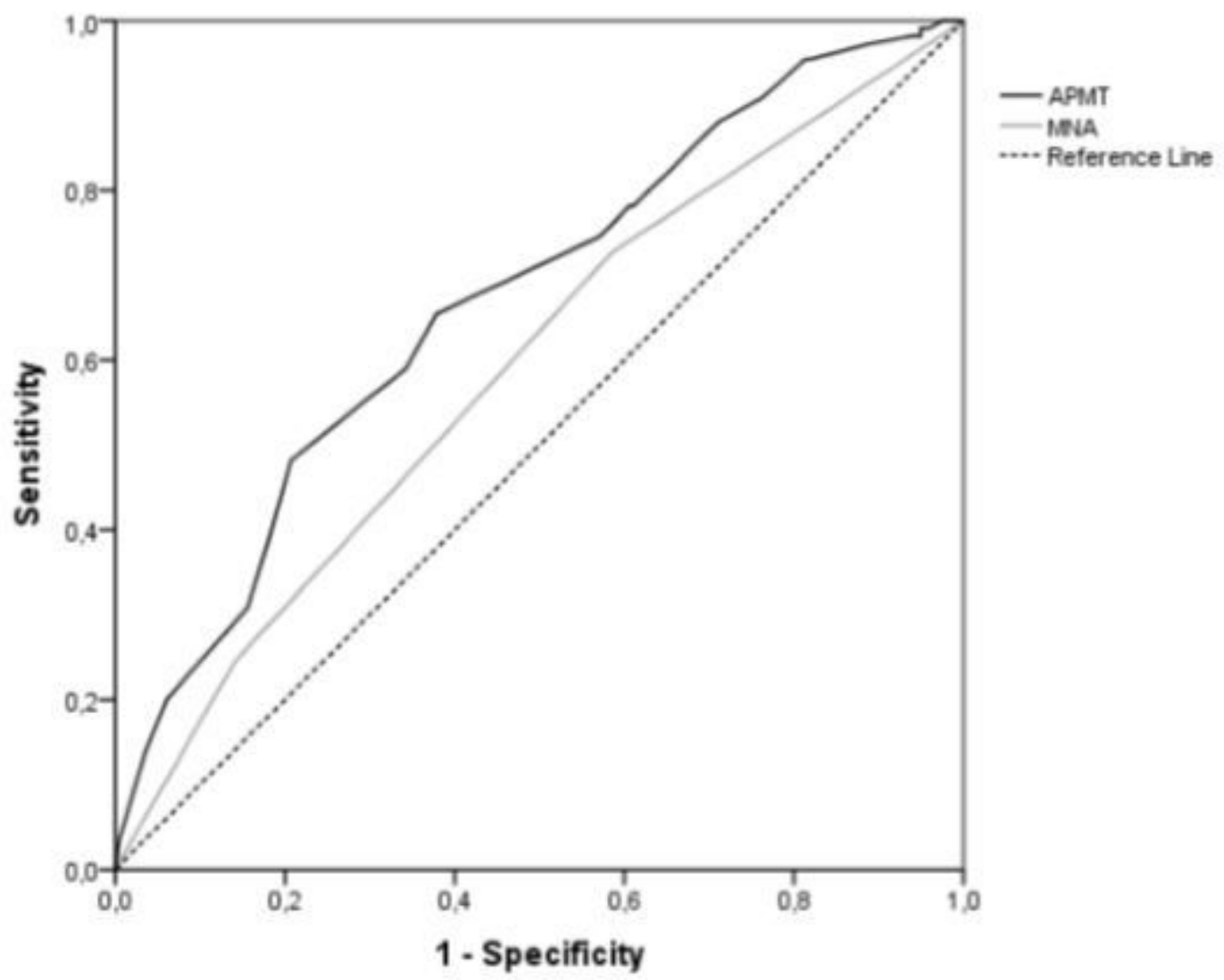

Area Under the Curve

\begin{tabular}{|c|c|c|c|c|}
\hline \multirow[b]{2}{*}{$\begin{array}{l}\text { Test Result } \\
\text { Variable(s) }\end{array}$} & \multirow[b]{2}{*}{ Area } & \multirow[b]{2}{*}{$\begin{array}{c}\text { Asymptotic } \\
\text { Sig. }\end{array}$} & \multicolumn{2}{|c|}{ Confidence Interval } \\
\hline & & & $\begin{array}{l}\text { Lower } \\
\text { Bound }\end{array}$ & $\begin{array}{l}\text { Upper } \\
\text { Bound }\end{array}$ \\
\hline APMT & 0.671 & 0.000 & 0.608 & 0.733 \\
\hline MNA & 0.591 & 0.008 & 0.525 & 0.657 \\
\hline
\end{tabular}

a. Under the nonparametric assumption

b. Null hypothesis: true area $=0.5$

\section{Figure 4}

Graph 2. ROC curve of MNA and APMT 